This is an Accepted Manuscript of an article published by Taylor \& Francis Group in Memory on 23/03/2017, available online: $h t t p: / / d x$.doi.org/10.1080/09658211.2017.1303073.

Trauma and Autobiographical Memory: Contents and Determinants of Earliest Memories among War-affected Palestinian Children 


\begin{abstract}
The contents of earliest memories (EM), as part of autobiographical memory, continue to fascinate scientists and therapists. However, research is scarce on the determinants of EM, especially among children. This study aims, first, to identify contents of EM of children living in war conditions, and, second, to analyze child gender, traumatic events and mental health as determinants of the contents of EM. The participants were 240 Palestinian schoolchildren from the Gaza Strip (10-12 years, $M=11.35, \mathrm{SD}=.57 ; 49.4 \%$ girls). They responded to an openended EM question, and reported their trauma exposures (war trauma, losses, and current traumatic events), posttraumatic stress, depressive symptoms and psychosocial wellbeing, indicating mental health. The EM coding involved nature, social orientation, emotional tone, and specificity. Results showed, first, that $43 \%$ reported playing or visiting a nice place as EM, and about a third (30\%) traumatic events or accidents $(30 \%)$ or miscellaneous events $(27 \%)$. The individual and social orientation were almost equally common, the emotional tone mainly neutral $(45.5 \%)$, and $60 \%$ remembered a specific event. Second, boys remembered more EM involving traumatic events or accidents, and girls more social events. Third, war trauma was associated with less positive emotional tone and with more specific memories.
\end{abstract}

Keywords: War, Children, Earliest Memory, Trauma, Mental Health 


\section{TRAUMA AND AUTOBIOGRAPHIC MEMORY}

Trauma and Autobiographical Memory: Contents and Determinants of

\section{Earlier Memories among War-affected Palestinian Children}

Many people believe that their earliest memories (EM) have a significant impact on their lives (van der Watt, Coal, Sng, \& Janca, 2016), and psychologists maintain that EM provide access to the focal issues that shape an individual's experience of the self and relations with others (Acklin, Sauer, Alexander, \& Dugoni, 1989). Remembering is always a process of mental reconstruction, not just playing back a recording of the past, and it therefore serves adaptation to current challenges and stressful events (Conway, 2005). Research is scarce on contents of children's EM in general, and especially among children living in stressful conditions of war or military violence. There is evidence among adults that mental health problems, such as depression and posttraumatic stress disorder (PTSD), can influence the nature and organization of autobiographical memory (for a review, see Moore \& Zoellner, 2007), but research is lacking concerning children. Accordingly, this study contributes to the EM literature by examining the contents of EM among Palestinian children who live in war conditions, and by analyzing child-, trauma-, and mental health related determinants of EM contents.

The psychological study of EM goes back to the Henris' pioneering survey on the EM of childhood (Henri \& Henri, 1897). They were the first to document the phenomenon of childhood amnesia, i.e., the inability to recall events that occur in the first years of one's life, typically before about three years of age. More recent research about the timing of EM is consistent with these original findings (MacDonald, Uesiliana, \& Hayne, 2000; Rubin, 2000; Tustin \& Hayne, 2010). Childhood amnesia is explained by children's cognitive and brain development and their communication skills (Morrison \& Conway, 2006; Nelson \& Fivush, 2004). A core precondition for verbal recollection of an experience is sufficient linguistic capacity at the time of encoding a memory. Simcock and Hayne (2002) observed that children could not verbally report information about an event that they had experienced at the age of 2-3 years if it involved issues that were 


\section{TRAUMA AND AUTOBIOGRAPHIC MEMORY}

not yet part of their productive vocabulary. Childhood amnesia can also be explained by the different goals that children have as compared to adults. Conway and Pleydell-Pearce (2000) propose that the goals of young children are related to their basic needs and, accordingly, the contents of their memories involve practical details of events, whereas adults engage in more complex activities with diverse goals. There is some evidence that access to early childhood memories becomes more difficult with age. For instance, adolescents can still remember some events from their childhood that are not accessible in adulthood (Peterson, Wang \& Hou, 2009; Tustin \& Hayne, 2010). This makes our participants, children 10-14 years of age, a particularly interesting group to study EM.

EM is regarded as an integral part of early autobiographical memory that starts to develop at the age of 5-6 years (Nelson \& Fivush, 2004; Peterson, Grant \& Boland, 2005). Generally, the findings suggest that children's early and more recent memories tend to be similar in terms of the amount of unique information provided, completeness of accounts, and use of specific narrative categories (van Abbema \& Bauer, 2005; Peterson, Fowler \& Brandeau, 2015). When probed for an early autobiographical memory, children have a large number of possible experiences to relate, and they must therefore use some criterion to select one specific event. Thus, the production of memories of one's own experiences is a reconstruction that is influenced by current circumstances. In Josselson's (2000, p. 462) view, the selected memory will typically be one that is relevant to the person's current concerns, hopes and human relations, representing "fundamental aspects of a person's inner experience in the present." According to the SelfMemory System model of autobiographical memory, memories that are coherent with and confirm one's goals and self-images are more accessible, while memories that contradict one's active self-image and personal goals (the "working self") will be inhibited and thus less accessible (Conway, 2005; Conway \& Pleydell-Pearce, 2000; McAdams, 2001). A stored 


\section{TRAUMA AND AUTOBIOGRAPHIC MEMORY}

memory of a meaningful event from the past can be seen as a person's characteristic way of creating and living in the world (McAdams, 1982).

Research suggests that child characteristics (e.g., gender and age), current life-events, stress and trauma, as well as current mental health influence the content and structure of autobiographical memory. Yet, empirical evidence is mixed. Some studies show that girls report more narrative, coherent, and longer autobiographical memories that contain more descriptive details (e.g., Buckner \& Fivush, 1998; Fivush, Hazzard, Sales, Sarfati, \& Brown, 2003; TizzardDrover \& Peterson, 2004). Concerning contents, a study found that girls reported more traumatic situations and more significant transitions, such as going to school, while boys reported more events involving games, play, and competition (Peterson, Pardy, Tizzard-Drover, \& Warren, 2005). On the contrary, some older studies found that boys remember more accident-related events than girls (e.g., Adcock, 1975; Schwartz, 1984). However, several studies have not found significant gender differences in the content or structure of children's autobiographical memories (e.g., Burgwyn-Bailes, Baker-Ward, Gordon, \& Ornstein, 2001; Fivush, Sales, \& Bohanek, 2008).

Traumatic experiences, i.e., events involving life threat, losses, and visual horrors, can have an especially strong impact on autobiographical memory (Dalgleish, Hauer \& Kuyken, 2008; Rubin, Berntsen \& Bohni, 2008). Research suggests, first, that traumatic events are not integrated into autobiographical memory, as traumatized people tend to omit the traumatic experiences from their life stories or distort them. Second, in cases where traumatized people do remember and tell about their traumatic experiences, the memories are fragmented and disorganized, and involve fewer details and narrative components than other autobiographical memories (Dalgleish et al., 2008; Salmond et al., 2011; Schönfeld, Ehlers, Böllinghaus, \& Rief, 2007). Third, the autobiographical memory of traumatized people is over-general, as they fail to report specific events and emotionally significant turning points events as a key life stories (Moore \& Zoellner, 


\section{TRAUMA AND AUTOBIOGRAPHIC MEMORY}

2007). There is an ample evidence that physically and sexually abused children and adolescents demonstrate more over-general autobiographical memory (OGM), more negative selfrepresentations and more difficulties with semantic personal memory compared to nonmaltreated children (Meesters, Merckelbach, Muris \& Wessel, 2000; Ogle et al., 2013; Valentino, Toth \& Cicchetti, 2009). Likewise, Brennen et al. (2010) showed that war-affected Bosnian and Serbian adolescents settled as refugees in Norway produced fewer specific autobiographical memories than the control group of native Norwegian adolescents. However, research is largely lacking on the role of traumatic experiences in affecting EM. We could detect only one empirical study, showing that a history of sexual abuse predicted the presence of malevolent representations in EM narratives among adult patients (Nigg et al., 1991).

A great number of studies have examined the associations between mental health and autobiographic memory, but findings are mixed. Some studies show that OGM is associated with depression in high-risk samples (e.g., Hipwell, Sapotichne, Klostermann, Battista, \& Keenan, 2011; Rawal \& Rice, 2012) and in the context of life stress in adolescence and early adulthood (Anderson, Goddard, \& Powell., 2010; Gibbs \& Rude, 2004; Hamlat et al., 2015; Stange, Hamlat, Hamilton, Abramson, \& Alloy, 2013; Sumner et al., 2011), while other studies have not found an association between OGM and depression (e.g., Brennen et al., 2010; Crane, Heron, Gunnell, Lewis, Evans \& Williams, 2016). Concerning children, those with posttraumatic stress disorder (PTSD) reported fewer specific memories than non-PTSD controls (Nixon, Ball, Sterk, Best \& Beatty, 2013). Again, there is much less evidence concerning EM. We could detect only two studies, both demonstrating an association between depression and less positive emotions in EM (Acklin, Bibb, Boyer, \& Jain, 1991; Richman \& Sokolove, 1992). To our knowledge, this is the first study examining both the effects of traumatic war experiences and mental health symptoms on the earliest memories of children. 


\section{TRAUMA AND AUTOBIOGRAPHIC MEMORY}

\section{Research Questions}

The first research task was to identify the content categories of earliest memories (EM) among Palestinian children living in war conditions. Specifically, we aimed to examine nature (trauma related vs. other memories), social orientation (social vs. individual memories), emotional tone (positive vs. negative memories) and the specificity (specific vs. generic memories) of the EM.

Second, we analyzed how gender, traumatic experiences (war trauma, losses, and current traumatic events), and mental health (posttraumatic stress and depressive symptoms, and psychosocial wellbeing) were related to the nature, social orientation, emotional tone, and specificity of the EM.

\section{Method}

\section{Participants and Procedure}

The participants were 240 Palestinian schoolchildren living in the Gaza Strip (10-12 years, $M=11.35, S D=.57 ; 49.4 \%$ girls). They formed the control group of an intervention study after the 2008/2009 war on Gaza. The original random sample for the intervention and control groups was from severely bombed areas in the Northern and Middle parts of the Gaza Strip. Sampling proceeded as follows: First, out of 160 schools in these areas eight schools were selected (every $20^{\text {th }}$ school on a list), taking into consideration that girls and boys attend separate schools. Second, at these eight schools sixth and seventh year classes were randomly chosen, resulting in 16 classes. Finally, the school classes were randomly divided into intervention and control groups of nearly equal sizes ( $n=242$ and $n=240)$, with $31-32$ students in each class. The present study thus involves the 240 control group children, who participated in measurements at three months after the Gaza War of 2008-2009 (T1 baseline), and at six (T2) and nine (T3) months follow-up. 


\section{TRAUMA AND AUTOBIOGRAPHIC MEMORY}

The present study employs data collected at T1 (war trauma, losses and gender) and T3 (earliest memories, mental health and current traumatic events).

The ethical boards of the Palestinian Ministry of Education and the Gaza Community Mental Health Programme (GCMHP) reviewed and accepted the study protocol and measurements. Permissions for the study were received from school authorities. Information sheets were prepared for the children and their parents explaining the purpose of the study, but only verbal consent for the target child to participate in the study was required. There were no refusals to participate. The research was part of routine schoolwork, agreed with the Ministry of Education and school head masters. Three female and three male research assistants conducted the fieldwork at the schools and children received detailed verbal and written instructions before they completed questionnaires. All questionnaires were in Arabic. The third author (SQ) supervised the fieldwork at the schools through weekly meetings with the school assistants. GCMHP provided consultation to families and teachers who so wished due to the high levels of worry of children in the aftermath of the 2008/09 war.

Measures and scoring system

Earliest memory (EM). The autobiographical memory enquiry started with the general instruction "Could you please scratch your memory and answer the questions below?" . Children were then asked about their EM with a standard procedure adopted from previous studies (Han, Leichtman, \& Wang, 1998; Wang, 2004, Wang \& Carole 2014). The instruction was: "You know, some kids can remember things that happened to them when they were very little. What is the first thing that you can remember?" The scoring procedure for EM was adapted from earlier studies (Peterson, Grant, \& Boland, 2005; Peterson, Wang, \& Hou, 2009; Peterson et al., 2015; Wang, 2001). Two raters (first and second author) independently scored memories for all participants. The inter-rater agreement was $100 \%$ for the nature, social orientation and specificity of the memories and $98 \%$ for the emotional tone of the memories. A third rater (outside of the 


\section{TRAUMA AND AUTOBIOGRAPHIC MEMORY}

research group) then scored the $2 \%$ of memories where disagreement existed, and the final scoring was based on a majority decision. The EM contents incorporate the following categories:

Existence of EM. There was two alternatives concerning children's early memories: (1) the child reported and described a memory or (2) the child explicitly reported of not recalling any memory.

Nature of event. Responses were classified into three mutually exclusive categories based on their contents: Trauma or accident (e.g., "It was war and the bombing came. We went to stay at our neighbours"); Playing or visiting a nice place (e.g., "We were all playing and celebrating my birthday"), or miscellaneous other events (many, but not all of them related to family meetings: e.g., "I saw my aunt for the first time", "I was standing beside my bed and screamed", "My grandmother gave me money to buy clothes", "My father bought me a bicycle"). (adapted from Peterson, Wang \& Hou, 2009).

Social orientation. Responses were classified into two mutually exclusive categories on the basis of the nature of social interaction of the actor in the memory. Social memories involved interactions with other people or the child being part of a group such as their family, school, or peers (e.g., "I was playing with my friends, brothers and sisters"). Individual memories involved children being alone or seeing and doing something independently (e.g., "I was walking to school, and a plane came...”). (Peterson, Grant, \& Boland, 2005; Peterson, Wang, \& Hou, 2009; Peterson et al., 2015; Wang, 2001).

Emotional tone. Responses were classified into three mutually exclusive categories on the basis of involving positive emotion (e.g., "I was happy when I ate cake and drank juice.”), negative emotion (e.g.,"My grandfather died. I was angry and sad.") or neutral (e.g., "I read the Koran at school"). (Peterson, Grant, \& Boland, 2005).

Specificity. Responses were classified into two mutually exclusive categories on the basis of the specificity of a memory. Specific memories describe a distinct and clear-cut event that 


\section{TRAUMA AND AUTOBIOGRAPHIC MEMORY}

occurred at a specific time and place (e.g., "Once I was asleep and the Israeli army came. My three uncles started to fight. A tank killed them all."). Generic memories describe events in a script-like or fragmented manner and refer to repeated and common events (e.g., "We used to go by the sea."). (Peterson, Wang, \& Hou, 2009; Wang, 2001).

War trauma. A checklist of 28 traumatic events was constructed for this study. It covers typical events during the War on Gaza 2008/09 and the military siege: (1) being personally a target of military violence, such as, being injured, or being exposed to shelling and bombardment, (2) family related losses, such as death of family member or eviction from home, (3) witnessing horrific scenes, such seeing somebody being killed or injured. Appendix I shows the content and frequencies of the war trauma checklist. Children reported at T1 whether they had experienced each traumatic event $(1=$ yes; $0=$ no). A sum variable was constructed by adding together the affirmative answers.

Losses. Children were asked at T1 whether they had lost any family member or other close persons. The alternatives provided were mother, father, brother, sister, close relative, intimate friend or classmate. Children answered either $1=$ yes or $0=$ no or for each type of loss. A sum variable of the number of losses was constructed.

Current traumatic events. The children were asked at T3 whether they had experienced any new traumatic events since the War on Gaza. They answered either $1=$ yes or $0=$ no.

Posttraumatic stress symptoms (PTSS). PTSS was measured using the 13-item Children's Revised Impact of Events Scale (CRIES; Smith, Perrin, Dyregrov, \& Yule, 2003) at T3. This self-report questionnaire includes four items relating to intrusion symptoms, four to avoidance and five to (hyper)arousal symptoms. Children evaluated on a 4 -point scale $(0=$ not at all, $1=$ rarely, $3=$ sometimes, $5=$ often) how often they had experienced a particular symptom over the last two weeks. Total scores on the questionnaire have a range of $0-65$. A cut-off score of 30 has been suggested for predicting a diagnosis of PTSD (Perrin, Meiser-Stedman, \& Smith, 2005). 


\section{TRAUMA AND AUTOBIOGRAPHIC MEMORY}

CRIES has shown adequate reliability and validity in Palestinian samples (Kolltveit et al., 2012). Cronbach's $\alpha$ was .63

Depressive symptoms. The Depression Self-Rating Scale for Children (DSRS; Birleson, 1981) of 18 items was used to measure depressive symptoms at T3. Children evaluated on a 3point scale how often they had experienced the described feelings $(0=$ mostly, $1=$ sometimes, 2 $=$ never $)$. The scale has a range of $0-36$. A cut-off score of 15 has been established to significantly predict a depressive diagnosis (Birleson, 1981). DSRS has shown moderate internal consistency in a Palestinian sample (Kolltveit et al., 2012) and has shown construct validity in an Iranian sample (Taghavi, 2006). Cronbach's $\alpha$ in this study was .66

Psychosocial wellbeing. The Mental Health Continuum-Short Form (MHC-SF) for youth (Keyes et al., 2008) was applied. Since the questionnaire was not available in Arabic it was translated and back-translated from and to English by the bilingual research group, and Palestinian members of the research group adjusted it to the socio-cultural context in Gaza. In this process one of the 14 items was deleted and two items were slightly changed. The 13 items assess the degree of emotional (positive affect, e.g. "I have warm and trusting relationships with others.") and psychological well-being (autonomy and self-acceptance, e.g., "I feel happy and social.", as well as social contribution and coherence, e.g., "My community has a good future"). Children evaluated on a 5-point scale how often they had experienced each particular feeling or thought during the past month $(0=$ never, $1=$ seldom $2=$ sometimes, $3=$ often, $4=$ every day $)$. A total sum variable was calculated with $\alpha=.85$.

Statistical Analysis

Determinants of the contents of EM were examined using binary logistic regression modeling in SPSS (version 22.0). The dependent variables were nature of event, social orientation, emotional tone and specificity of the EM, and independent variables were decided according to the results of correlation analysis. For the purposes of binary logistic regression 


\section{TRAUMA AND AUTOBIOGRAPHIC MEMORY}

analyses, the emotional tone was split into two binary conditions: each memory was recoded as "positive vs. negative or neutral" and as "negative vs. positive or neutral". Similarly, for nature of event, each memory was coded as "trauma or accident vs. play or going to a nice place/miscellaneous other" and as "play or going to a nice place vs. trauma or accident/miscellaneous other".

A commonly applied rule of thumb states that logistic regression models should include a minimum of 10 target events per predictor variable (Peduzzi, Concato, Kemper, Holford \& Feinstein, 1996). For this reason, all potential predictors could not be included in all constructed regression models at once. Therefore, we first analyzed the Pearson point-biserial-correlations between the dependent variables and seven potential predictors: gender, war trauma, current traumatic event, losses, depression, PTSS and psychosocial wellbeing. Potential predictors with at least marginally significant $(p<.10)$ correlations were then selected for inclusion in logistic regression models for nature of event, social orientation, emotional tone and specificity of EM (Table 1).

None of the independent variables in the primary models had a standard error greater than 2.0, which indicated there was no evidence of multicollinearity (Schwab, 2007). Logistic regression coefficients were used to estimate odds ratios with $95 \%$ confidence intervals $(\mathrm{CI})$ for each of the independent variables in the models.

\section{Results}

\section{Descriptive Statistics}

Of the total sample $49 \%$ were girls. The majority lived in urban areas (86\%), $12 \%$ in refugee camps and $3 \%$ in villages. A quarter of fathers $(25 \%)$ and $8 \%$ of mothers had a university level education, while $24 \%$ of fathers and $42 \%$ of mothers had completed secondary level 


\section{TRAUMA AND AUTOBIOGRAPHIC MEMORY}

education. Mothers were on average 37.6 and fathers 42.4 years old. There was a high rate of unemployed fathers (49\%), which corresponds to general Palestinian statistics in the Gaza Strip during the international siege and economic blockade (UN:OCHA, 2009). As regards their mental health, $32.9 \%$ of the children exhibited PTSS scores above the clinical cutoff line, while 41.1\% had depression scores above the clinical cutoff.

Table 1 presents the frequencies of war trauma conceptualized as child-targeted, family losses, witnessing horrors and material destruction. Almost a quarter of children reported being injured during the war (23\%) and $19 \%$ were burned. Family losses were common, as $82.5 \%$ had to leave their home and $32 \%$ were separated from their families. Three quarters (77\%) of children witnessed shooting, and 59-63\% had seen people injured and killed. Material destruction was common, e.g., loss of source of income and family property (60-61\%).

Insert Table 1. about here

Out of 240 participants, 188 answered the open question about their EM. The groups providing and not providing responses to the question did not differ in terms of their gender, exposure to war trauma, losses, current traumatic experiences, depressive symptoms or psychosocial wellbeing. However, children who did answer the question about their EM had more PTSS $(M=26.82, S D=9.30)$ than those who did not $(M=22.19, S D=8.14), t(195)=$ $2.94, p=.004,95 \% \mathrm{CI}_{\text {diff }}[1.75,7.51]$, Hedges's $g_{s}=.51$. Out of 188 respondents, $110(58.5 \%)$ recounted an EM, while $78(41.5 \%)$ reported they did not remember an EM. According to $t$ tests, the groups describing and not describing a memory did not differ significantly in their

gender, war trauma, losses, current traumatic experiences, PTSS, depressive symptoms, or psychosocial wellbeing.

Identified Contents of Earliest Memories

Table 2 presents the distribution of the contents of children's EM. Concerning the nature of EM, the result showed that memories involving playing and visiting a nice place were more 


\section{TRAUMA AND AUTOBIOGRAPHIC MEMORY}

common (43\%) than memories of trauma or accident $(30 \%)$ or miscellaneous other $(27 \%)$ memories. EM with an individual orientation were slightly more common (55\%) than those with a social and group orientation (45\%). One third of the children (31\%) reported EM involving negative emotions, while $29 \%$ had a positive and $49 \%$ a neutral emotional tone in their memories. Of the children, $60 \%$ remembered a specific event and $40 \%$ described a more generic situation as their EM.

Insert Table 2 about here

Predictors for Earliest Memory Contents

Table 3 shows the Pearson point-biserial-correlations between child-, trauma- and mental health-related factors and EM content categories. Child gender, war trauma and PTSS and psychosocial wellbeing were significantly correlated with the contents of the children's EM. Results showed that child gender, war trauma and posttraumatic symptoms correlated with contents of EM. Female gender positively correlated with social and group orientation, and negatively with trauma and accident as EM and negative emotional tone of EM. High levels of war trauma was negatively correlated with the positive emotionality of EM and positively with the specificity of EM. In contrast to other EM categories, there were no significant correlations between the existence of an EM and any potential predictors.

Insert Table 3 about here

Table 4 presents the logistic regression analyses of child-, trauma- and mental healthrelated factors predicting the content categories of EM. All models of logistic regression analyses fitted well to the data (The Omnibus Tests of Model Coefficients for all models $\mathrm{p}<.05$, and the Likelihood Ratio $\chi^{2}$ test for all models $\left.\mathrm{p}>.05\right)$. The Nagelkerke pseudo- $\mathrm{R}^{2}$ of the models were .06 for nature of Event, .12 for social orientation, .05 for negative emotionality, .18 for positive emotionality and .11 for specificity. The Nagelkerke pseudo- $\mathrm{R}^{2}$ in logistic regression analysis should be treated as a measure of effect size, similar to how $\mathrm{R}^{2}$ is treated in standard OLS 


\section{TRAUMA AND AUTOBIOGRAPHIC MEMORY}

regression. However, it does not represent the amount of variance in the outcome variable accounted for by the predictor variables. Higher values indicate better fit, but they should be interpreted with caution.

The models revealed one to three significant predictors for nature, social orientation, emotional tone and specificity of EM (Table 4). The results show that child- and trauma-related factors were significantly associated with the content of children's EM, whereas mental health did not play a role. The results show that boys had 2.58 times higher odds of remembering trauma and accident related events rather than playing and visiting nice places or miscellaneous other events as compared with girls. Girls had 2.27 times higher odds of remembering events that involved social interactions rather than memories with individual orientation, as compared with boys. Higher levels of war trauma were associated with a lower likelihood of remembering a positive rather than a neutral or negative event as $\mathrm{EM}(\mathrm{OR}=0.87$, per additional traumatic event experienced). Also, higher levels of war trauma were associated with a higher likelihood of remembering a specific event rather than a generic $\mathrm{EM}(\mathrm{OR}=1.16$, per additional traumatic event experienced). The amount of losses experienced by children did not predict EM contents. Post traumatic stress- and depressive symptoms did not associate with EM contents. Similarly, psychosocial wellbeing was not associated with the content of children's EM.

\section{Insert Table 4. here}

\section{Discussion}

Earliest memories can carry important meanings also for children, and they may serve an important function in making sense of life stories in violent environments. The studied Palestinian children reported pleasant memories of play and nice places relatively often (43\%), while "only" a third reported traumatic events and accidents. The emotional tone was equally often negative and positive $(26 / 28 \%)$, and almost a half of EM were emotionally neutral. A 


\section{TRAUMA AND AUTOBIOGRAPHIC MEMORY}

majority remembered a specific event, and there were equally individual and social group orientations. We could not detect earlier studies on the contents of EM among war-affected children or children from other than western countries, and thus commenting the distribution is not easy.

Mental health problems are often studied among children living in war areas (e.g., Werner, 2012), but less attention is paid to cognitive processes such as autobiographical memory. Our finding concerning the determinants of EM contradict with earlier research in that children's mental health problems of PTSD or depression were not associated with the EM. Also, children exposed to severe war trauma did not show more generalized memories, which opposes the idea of over-general memory OGM among trauma survivors. We did not pose hypotheses concerning the contents of EM as earlier research among children is very rare. However, intuitively it may be unexpected that memories of childhood memories involving play and memorable visits exceeded to those of trauma- and accident-related memories among participating Palestinian children in Gaza. Their occurrence closely corresponds with EM in studies among children living in peaceful and safe environments. Research among North-American children found that about a quarter of their EM involved traumatic or accident events (Mullen, 1994; Peterson et al., 2005), while the share of such memories in our data was about one third (30\%). Moreover, the emotional tone in their EM was often neutral, and only in about third negative.

The political and military developments in the Gaza Strip do not explain the result that children's EM had more pleasant and normative children's activities than traumatic or threatening contents. The participating children have grown up under very unstable political and military conditions, although the period when they were born, in 1996-1999, was relatively peaceful, characterized with the hopes for peace due to the Oslo Accords of 1993. Yet, their preschool years were already overshadowed by the heavy Israeli military reprisals to suppress the Palestinian uprising (Second Intifada in 2000-2004). The military violence culminated in the 


\section{TRAUMA AND AUTOBIOGRAPHIC MEMORY}

War on Gaza 2008/09 when the children were 11-13 year-olds. The results thus suggest that external threat and violence seem not to be reflected in EM since the prevalence of EM with trauma and accident contents did not differ from those in peaceful societies (Mullen, 1994; Peterson et al., 2005).

The family dynamics and adaptive function of memories may explain the relative pleasant and neutral quality of childhood memories in dangerous environments. Parents attempt to make all they can to guarantee children a normal childhood in war conditions. Research on transgenerational transmission of trauma confirm parents' high motivation of securing and protecting their children from awareness of dangers (Giladi \& Bell, 2013). For instance, Palestinian mothers exposed to severe war trauma showed especially high attachment to their children (Palosaari, Punamäki, Qouta, \& Diab, 2013). The high parental investments in their offspring was thus reflected in the atmosphere of safety and neutrality of children's early memories. Furthermore, remembering is a constructed, adaptive, and meaning-seeking process (Conway, 2005), and pleasant and caring memories can contribute to children's self-esteem and wellbeing, and provide encouragement and condolence in current life threat and insecurity.

The participants in this study live in collectivistic Islamic Middle Eastern society, where values emphasize family affiliation, social cohesion, and physical closeness and harmony (Keller, 2006). According to our findings, the EM of the Palestinian children involved 55\% individual orientation, whereas the corresponding share was $86 \%$ among children in more individualistic Canadian society (Peterson et al., 2005). In this sense our results support the premises of cultural psychology on cultural scripts and values shaping learning, social interaction and cognitive processes such as memory (Keller, 2006; Poortinga, 2008). Yet, it is noteworthy that individual (55\%) and social and group (45\%) orientation were almost as common in the EM of these Palestinian children. Thus, the culturally salient collectivistic orientation was not as clearly visible in our Middle Eastern sample as it was in the early (though not necessarily earliest) 


\section{TRAUMA AND AUTOBIOGRAPHIC MEMORY}

memories of Chinese children in one earlier study, where $67 \%$ of the memories had a social element (Peterson et al., 2009).

Concerning predictors of the content of EM, our findings show that girls tended to remember more play and nice visiting scenes, and boys more traumatic events and accidents. In contrast, Peterson et al. (2005) found that girls' EM involved more traumatic and accident related events, while boys' EM were commonly related to play activities characterized by competition and game. In war areas, such as Palestine, boys typically encounter more traumatic events than girls, who are more protected (Peltonen, Qouta, Diab \& Punamäki, 2014), which may partly explain the results on gender differences. However, trauma exposure did not associate with the nature of EM in our study.

Children's exposure to severe war trauma in the recent past was associated with more specific and detailed descriptions of EM, while less exposed children reported more generic memories. The result is in contrast with the research on overgeneralized memory, OGM, among young trauma survivors (Dalgleish et al., 2008; Salmond et al., 2011; Schönfeld et al., 2007). It is important to note, however, that the results on OGM are based on autobiographic memories that involve a wider narrative data. Future studies should raise an important question as to whether EM in a traumatic environment have a specific and somehow different role than later episodes in autobiographical memory. Also, rather the mental health consequences of trauma are associated with autobiographic OGM, and not often the exposure to trauma itself (for a review see, Moore \& Zoellner, 2007). On the other hand, research on peritraumatic dissociation indicates that typically highly traumatized victims remember details of the overwhelming events and report recalling specific sensory modalities such as smells or voices (Schauer \& Elbert, 2015). Yet, our coding system did not include scores for verbal, behavioral or sensory modalities of the EM.

Unlike earlier studies (e.g., Acklin et al., 1991; Richman \& Sokolove, 1992) children's mental health, as indicated by depressive and PTSD symptoms and psychosocial wellbeing, was 


\section{TRAUMA AND AUTOBIOGRAPHIC MEMORY}

not associated with the contents of their EM. However, the mental health was associated with the occurrence of EM, as children who did answer the question about their EM showed more PTSD symptoms than those who did not answer this question at all. The result is not in line with observations that ability to narrate and provide descriptions of experiences is associated with lower levels of PTSS (van der Kolk, 2000). Further examination is needed to find out the special features of EM among traumatized children.

Developmental aspects could further explain the absent association of current mental health problems in the EM. The earliest memories are encoded at a very young age around 4-5 years, and it is possible that severe traumatic events and the time of encoding would play a more important role than later psychopathology. It is known that episodic autobiographical elements, such as personal events with reference to oneself and emotionally significant events, develop later than semantic autobiographical memory, i.e., knowledge that the events happened (Piolino, 2007). A social explanation of the association between the number of traumatic events and EM specificity would lie in these children's social context and the collective experience of trauma. For example, given that the war affected a significant proportion of the Gazan population, it is possible that the children, their families, teachers, friends, and others would all recount what happened or hear about it from the media. Hence, the memories of certain events would have become much more accessible for recall due to over-rehearsal.

Study limitations and future research

Many systems of enquiry previously developed have asked for several different early memories and followed up by various enquiries for further details (e.g. Bruhn, 1992; Karliner, Westrich, Shedler, \& Mayman, 1996; Peterson, Wang, \& Hou, 2009; Tustin \& Hayne, 2010). In this study, the children were only asked to describe a single EM, and no further queries were made. It is possible that this single enquiry was not able to capture the breadth of the phenomenon of EM. However, this single direct question does most clearly focus the search on the one 


\section{TRAUMA AND AUTOBIOGRAPHIC MEMORY}

memory that is judged to be the very earliest and may provide us with less biased free recall memories. In any case, the very high variability in the types of queries used, with regards to how many and what type of memories were asked for and what, if any, follow-up questions were made, makes comparison to the findings of earlier studies difficult. The standardization of an EM enquiry protocol could be the next step in the field.

Children were not asked at what age they experienced the situation they reported as their EM. The phenomenon of childhood amnesia should be further studied in war conditions. It is also possible that children have already lost some of their earliest memories, since the study of van Abbema and Bauer (2005) showed that school-aged can remember only half of the events that they had recalled at the age of three.

It is also noteworthy that many of the studies examining EM (e.g., Bauer \& Larkina, 2014; Wang, 2006) have used a cue-word method, where participants try to recall an event related to a given cue word. In our study, a free recall method without cue words was used. This might have affected the response rate and also merits caution in comparing the results.

One of the categories developed in earlier studies of EM had to be adapted slightly to fit our sample. In the original coding scheme of Peterson et al. $(2005 ; 2015)$, the events were classified as involving trauma, play, transition or miscellaneous other. However, we could find few descriptions of transitions (such as first day at school) in our sample but instead found many descriptions of severe accidents, which were added as another category in the scoring. The modest Nagelkerke pseudo- $\mathrm{R}^{2}$ values indicate that the fit of the regression models of EM categories was not very good. A larger data set should be collected in order to test the accuracy of the results.

The findings should be interpreted cautiously, as the reliabilities of depressive and post traumatic stress disorder symptom measures were only moderate in the sample. Although the 


\section{TRAUMA AND AUTOBIOGRAPHIC MEMORY}

Arabic versions of the measures have been shown good reliabilities in earlier studies (Barron et al. 2012; Kolltveit et al. 2012), they didn't work optimally in our sample.

Taken together, our study contributes to our understanding of a specific aspect of autobiographical memory, namely the earliest memories of children. One of the most studied phenomenon of autobiographical memory, overgenerality, seems to not follow the same rules among war affected children and their earliest memories as among adults or as regards children's lifetime autobiographical memories. This finding needs further evaluation. 
TRAUMA AND AUTOBIOGRAPHIC MEMORY

References

van Abbema, D. L., \& Bauer, P. J. (2005). Autobiographical memory in middle childhood: Recollections of the recent and distant past. Memory, 13, 829-845. doi:

$10.1080 / 09658210444000430$

Acklin, M. W., Bibb, J. L., Boyer, P., \& Jain, V. (1991). Early memories as Expressions of Relationship Paradigms: A Preliminary Investigation. Journal of Personality Assessment, 57(1), 177-192. doi: 10.1207/s15327752jpa5701_19

Acklin, M. W., Sauer, A., Alexander, G., \& Dugoni, B. (1989). Predicting depression using earliest childhood memories. Journal of Personality Assessment. 53, 51-59. DOI:

10.1207/s15327752jpa5301_6

Adcock, N. V. (1975). Early memories and sex differences. New Zealand Psychologist, 4, 3034.

Anderson, R. J., Goddard, L., \& Powell, J. H. (2010). Reduced specificity of autobiographical memory as a moderator of the relationship between daily hassles and depression. Cognition and Emotion, 24(4), 702-709. doi: 10.1080/02699930802598029

Barron, I. G., Abdallah, G., \& Smith, P. (2012). Randomized control trial of a CBT trauma recovery program in Palestinian schools. Journal of Loss and Trauma: International Perspectives on Stress \& Coping, 18, 306-321. doi:10.1080/15325024.2012.688712.

Bauer, P. \& Larkina, M. (2014). Childhood amnesia in the making: Different distributions of autobiographical memories in children and adults. Journal of Experimental Psychology:

General, 143(2), 597-611. DOI: 10.1037/a0033307

Birleson, P. (1981). The validity of depressive disorder in childhood and the development of a self-rating scale: a research report. Journal of Child Psychology and Psychiatry, 22, 73-88. DOI: 10.1111/j.1469-7610.1981.tb00533.x 


\section{TRAUMA AND AUTOBIOGRAPHIC MEMORY}

Brennen, T., Hasanović, M., Zotović, M., Blix, I., Skar, A-M. S., Prelić, N. K., Mehmedović, I., ... Gavrilov-Jerković, V. (2010). Trauma exposure in childhood impairs the ability to recall specific autobiographical memories in late adolescence. Journal of Traumatic Stress, 23, 240247. doi: 10.1002/jts.20513

Bruhn, A. R. (1992). The early memories procedure: A projective test of autobiographical memory, part 1. Journal of Personality Assessment, 58(1), 1-15. doi:

10.1207/s15327752jpa5801_1

Buckner, J. P., \& Fivush, R. (1998). Gender and self in children's autobiographical narratives. Applied Cognitive Psychology, 12, 407-429. doi: 10.1002/(SICI)10990720(199808)12:4<407::AID-ACP575>3.0.CO;2-7

Burgwyn-Bailes, E., Baker-Ward, L., Gordon, B. N., Ornstein, P. A. (2001). Children's Memory for Emergency Medical Treatment after One Year: The Impact of Individual Difference Variables on Recall and Suggestibility. Applied Cognitive Psychology, 53, 25-48. doi: $10.1002 /$ acp. 833

Conway, M. A., \& Pleydell-Pearce, C. W. (2000). The construction of autobiographical memories in the self-memory system. Psychological Review, 107, 261-88. DOI:

10.1037//0033-295X .107.2.261

Conway, M. A. (2005) Memory and the self. Journal of Memory and Language, 53, 594-628. doi:10.1016/j.jml.2005.08.005

Crane, C., Heron, J., Gunnel, D., Lewis, G., Evans, J., \& Williams, J. M. (2016). Adolescent over-general memory, life events and mental health outcomes: Findings from a UK cohort study. Memory, 24, 348-363. doi: 10.1080/09658211.2015.1008014

Dalgleish, T., Hauer, B., \& Kuyken, W. (2008). The mental regulation of autobiographical recollection in the aftermath of trauma. Current Directions in Psychological Science, 17, 259263. doi: 10.1111/j.1467-8721.2008.00586.x 


\section{TRAUMA AND AUTOBIOGRAPHIC MEMORY}

Fivush, R., Haden, C. A., \& Adam, S. (1995). Structure and coherence of preschoolers' personal narratives over time: Implications for childhood amnesia. Journal of Experimental Child Psychology, 60, 32-56. doi: 10.1006/jecp.1995.1030

Fivush, R., Hazzard, A., McDermott Sales, J., Sarfati, D. \& Brown, T. (2003). Creating coherence out of chaos? Children's narratives of emotionally positive and negative events. Applied Cognitive Psychology, 17, 1-19. doi:10.1002/acp.854

Fivush, R., McDermott Sales, J., \& Bohanek, J. G. (2008) 'Meaning making in mothers' and children's narratives of emotional events'. Memory, 16, 579-594. DOI:

$10.1080 / 09658210802150681$

Giladi, L., \& Bell, T. S. (2013). Protective factors for intergenerational transmission of trauma among second and third generation Holocaust survivors. Psychological Trauma: Theory, Research, Practice, and Policy, 5, 344-391. doi: 10.1037/a0028455

Gibbs, B. R., \& Rude, S. S. (2004). Overgeneral Autobiographical Memory as Depression Vulnerability. Cognitive Therapy and Research, 28, 511-526.

doi:10.1023/B:COTR.0000045561.72997.7c

Hamlat, E. J., Connolly, S. L., Hamilton, J. L., Stange, J. P., Abramson, L. Y., \& Alloy, L. B. (2015). Rumination and Overgeneral Autobiographical Memory in Adolescents: An Integration of Cognitive Vulnerabilities to Depression. Journal of Youth and Adolescence, 44, 806-818. DOI: $10.1007 / \mathrm{s} 10964-014-0090-2$

Han, J. J., Leichtman, M. D., \& Wang, Q. (1998). Autobiographical memory in Korean, Chinese, and American children. Developmental Psychology, 34, 4, 701-713. DOI: 10.1037//0012-1649.34.4.701

Henri, V., \& Henri, C. (1897). Enquête sur les premiers souvenirs de l'enfance. L'Année Psychologique, 3, 184-198. Translated in: Nicolas, S. ,Gounden, Y., \& Pioline, P. (2013). Victor and Catherine Henri on earliest recollections. L'Année Psychologique, 113(3), 349-374. doi: $10.4074 /$ S0003503313003035 


\section{TRAUMA AND AUTOBIOGRAPHIC MEMORY}

Hipwell, A. E., Sapotichne, B., Klostermann, S., Battista, D., \& Keenan, K. (2011). Autobiographical memory as a predictor of depression vulnerability in girls. Journal of Clinical Child \& Adolescent Psychology, 40(2), 254-65. doi: 10.1080/15374416.2011.546037

Josselson, R. (2000). Stability and change in early memories over 22 years: Themes, variations, and cadenzas. Bulletin of the Menninger Clinic, 64(4), 462-481.

Karliner, R., Westrich, E., Shedler, J., \& Mayman, M. (1996). The Adelphi early memory index: Bridging the gap between psychodynamic and scientific psychology. In: Masling, J., Bornstein, R. (Eds.). Psychoanalytic perspectives on developmental psychology (pp. 43-67). Washington, DC: APA.

Keller, H. (2006). Cultures of Infancy. Boston: Lawrence Elbraum Associates Inc.

McAdams, D. P. (1982). Experiences of intimacy and power: Relationships between social motives and autobiographical memory. Journal of Personality and Social Psychology, 42, 292 302. doi 10.1037/0022-3514.42.2.292

Kolltveit, S., Lange-Nielsen, I. I., Thabet, A. A. M., Dyregrov, A., Pallesen, S., Johnsen, T. B., \& Laberg, J. C. (2012). Risk factors for PTSD, anxiety, and depression among adolescents in Gaza. Journal of Traumatic Stress, 25, 164-170. doi:10.1002/jts.21680.

van der Kolk, B. (2000). Posttraumatic stress disorder and the nature of trauma. Dialogues in Clinical Neuroscience, 2(1), 7-22.

MacDonald, S., Uesiliana, K., \& Hayne, H. M., (2000). Cross-cultural and gender differences in childhood amnesia. Memory, 8, 365-376. http://dx.doi.org/10.1080/09658210050156822

Meesters, C., Merckelbach, H., Muris, P., \& Wessel, I. (2000). Autobiographical memory and trauma in adolescents. Journal of Behavior Therapy and Experimental Psychiatry, 31(1), 438446. 


\section{TRAUMA AND AUTOBIOGRAPHIC MEMORY}

Moore, A. \& Zoellner, L.A. (2007). Overgeneral Autobiographical Memory and Traumatic Events. An Evaluative Review. Psychological Bulletin, 133, 419-437. doi: 10.1037/00332909.133.3.419

Morrison, C. M. \& Conway, M.-A. (2010). First words and first memories, Cognition, 116, 23-32. doi: 10.1016/j.cognition.2010.03.011.

Mullen, M. K. (1994). Earliest recollections of childhood: a demographic analysis. Cognition, 52(1), 55-79. doi: 10.1016/0010-0277(94)90004-3

Nelson, K. \& Fivush, R. (2004). The emergence of autobiographical memory: A social cultural developmental theory. Psychological Review, 111(2), 486-511. doi: 10.1037/0033295X.111.2.486

Nigg, J., Silk, K., Westen, D., Lohr, N., Gold, L., Goodrich, S., \& Ogata, S. (1991). Object representations in the early memories of sexually abused borderline patients. American Journal of Psychiatry, 148(7), 864-869. doi: 10.1176/ajp.148.7.864

Nixon, R. D. V., Ball, S-A., Sterk , J., Best, T., \& Beatty, L. (2013). Autobiographical Memory in Children and Adolescents With Acute Stress and Chronic Posttraumatic Stress Disorder. Behaviour Change, 30, 180-198. doi: https://doi.org/10.1017/bec.2013.17

Ogle, C. M., Block, S. D., Harris, L. S., Goodman, G. S., Pineda, A., Timmer, S., Urquiza, A., \& Saywitz, K. J. (2013). Autobiographical memory specificity in child sexual abuse victims. Developmental Psychopatholoy, 25, 321-332. doi: 10.1017/S0954579412001083

Palosaari, E., Punamäki, R-L., Qouta, S., \& Diab, M. (2013). Intergenerational effects of war trauma among Palestinian families mediated via psychological maltreatment. Child Abuse \& Neglect, 37(11), 955-968. doi: 10.1016/j.chiabu.2013.04.006

Peduzzi, P., Concato, J., Kemper, E., Holford, T. R., \& Feinstein, A. R. (1996). A simulation study of the number of events per variable in logistic regression analysis. Journal of Clinical Epidemiology, 49, 1373-1379. doi: 10.1016/S0895-4356(96)00236-3 


\section{TRAUMA AND AUTOBIOGRAPHIC MEMORY}

Peltonen, K., Qouta, S., Diab, M., \& Punamäki, R-L. (2014). Resilience among children in war: The role of multilevel social factors. Traumatology, 20, 232-240. doi:10.1037/h0099830

Peterson, C., Grant, V. V., \& Boland, L. D. (2005). Childhood amnesia in children and adolescents: Their earliest memories. Memory, 13(6), 622-637. doi:

$10.1080 / 09658210444000278$

Peterson, C., Pardy, L., Tizzard-Droven, T., \& Warren, K.L. (2005). When initial interviews are delayed a year: effect on children's 2-year recall. Law and Human Behavior, 29, 257-241. doi: 10.1007/s10979-005-6833-6

Peterson, C., Wang, Q., \& Hou, Y. (2009). "When I was little": Childhood recollections in Chinese and European Canadian grade school children. Child Development, 80, 506-518. doi: 10.1111/j.1467-8624.2009.01275.x

Peterson, C., Fowler, T., \& Brandeau, K.M., (2015). Earliest Memories and Recent Memories of Highly Salient Events-Are They Similar? Journal of Cognition \& Development, 16, 638649. doi: 10.1080/15248372.2013.879872

Piolino, P., Hisland, M., Ruffeveille, I., Matuszewski, V., Jambaqué, I., \& Eustache, F. (2007). Do school-age children remember or know the personal past? Consciousness and Cognition, 16(1), 84-101. doi 10.1080/15248372.2013.879872

Rawal, A., \& Rice, F. (2012). Examining overgeneral autobiographical memory as a risk factor for adolescent depression. Journal of American Academy of Child and Adolescent Psychiatry, 51, 518-527. doi: 10.1016/j.jaac.2012.02.025

Richman, N., \& Sokolove, R. (1992). The experience of aloneness, object representation and evocative memory in borderline and neurotic patients. Psychoanalytic Psychology, 49, 77-91. doi: $10.1037 / \mathrm{h} 0079323$ 


\section{TRAUMA AND AUTOBIOGRAPHIC MEMORY}

Rubin, D. C, Berntsen, D., \& Bohni M. K. (2008). A memory-based model of posttraumatic stress disorder: evaluating basic assumptions underlying the PTSD diagnosis. Psychological Review, 115, 985-1011. doi: 10.1037/a0013397

Rubin, D. C. (2000). The distribution of early childhood memories. Memory, 8(4), 265-269.

Salmond, C.H., Meiser-Stedman, R.,Glucksman, E., hompson,. T.,Dalgleish, T., \& Smith, P. (2011). The nature of trauma memories in acute stress disorder in children and adolescents. Journal of Child Psychology and Psychiatry, 52, 560-570. doi.

Schauer, M., \& Elbert, T. (2015). Dissociation following traumatic stress. Zeitschrift für Psychologie/Journal of Psychology., 218(2), 109-127. doi: 10.107/0044-3409/a000018

Schwab J. (2007). Multinomial Logistic Regression Basic Relationships. www.utexas.edu/courses/schwab/sw388r7/SolvingProblems/Analyzi.

Schwartz, A. E. (1984). Earliest memories: Sex differences and the meaning of experience. Imagination, Cognition and Personality, 4, 43-52. doi: 10.2190/FU5L-WKQC-YX5F-3BU8

Schönfeld, S., Ehlers, A., Böllinghaus, I., \& Rief, W. (2007). Overgeneral memory and suppression of trauma memories in post-traumatic stress disorder. Memory, 15, 339-352. doi: $10.1080 / 09658210701256571$

Simcock, G., \& Hayne, H. (2002). Breaking the barrier? Children fail to translate their preverbal memories into language. Psychological Science, 13, 225-231. doi: 10.1111/14679280.00442

Smith, P., Perrin, S., Dyregrov, A., \& Yule, W. (2003). Principal components analysis of the impact of event scale with children in war. Personality and Individual Differences 34, 315-322. doi: 10.1016/S0191-8869(02)00047-8

Stange, J.P., Hamlat, E.J., Hamilton, J.L., Abramson, L.Y, \& Alloy, L.B. (2013). Overgeneral autobiographical memory, Emotional maltreatment, and depressive symptoms in adolescence: 


\section{TRAUMA AND AUTOBIOGRAPHIC MEMORY}

Evidence of a cognitive vulnerability-stress interaction. Journal of Adolescence. 36, 201-208. doi: 10.1016/j.adolescence.2012.11.001

Sumner, J. A., Griffith, J. W., Mineka, S., Rekart, K. N., Zinbarg, R. E., \& Craske, M. G. (2011). Overgeneral autobiographical memory and chronic interpersonal stress as predictors of the course of depression in adolescents. Cognition \& Emotion, 25, 183-192. doi: $10.1080 / 02699931003741566$

Taghavi, M. R. (2006). Factor structure of the depression self-rating scale in an Iranian adolescent sample. Psychological Reports, 99, 709-716. http://dx.doi.org/10.2466/PR0.99.3.709-716

Tizzard-Drover, T.,\& Peterson, C.. (2004). The influence of an early interview on long-term recall: a comparative analysis. Applied Cognitive Psychology,18, 727-743.doi: 10.1002/acp. 1028

Tustin, K. \& Hayne, H. (2010). Defining the boundary: Age-related changes in childhood amnesia. Developmental Psychology, 46, 1049-1061. doi:10.1037/a0020105

UN:OCHA, 2009. Human rights in Palestine and other occupied Arab territories: Report of the United Nations Fact Finding Mission on the Gaza Conflict. Human Rights Council, $\mathrm{A} / \mathrm{HRC} / 12 / 48$.

Valentino, K., Toth, S. L., \& Cicchetti, D. (2009). Autobiographical memory functioning among abused, neglected, and nonmaltreated children: The overgeneral memory effect. Journal of Child Psychology and Psychiatry, 50, 1029-1038. doi: 10.1111/j.1469-7610.2009.02072.x

Wang, Q. (2001). Culture effects on adults' earliest childhood recollection and self-description: Implications for the relation between memory and the self. Journal of Personality and Social Psychology, 8(1), 220-233. doi: 10.1037/0022-3514.81.2.220 
Wang, Q. (2006). Earliest recollections of self and others in European American and Taiwanese Young Adults. Psychological Science, 17(8), 708-714. DOI: 10.1111/j.14679280.2006.01770.x.

Wang, Q. (2004). The emergence of cultural self-constructs: Autobiographical memory and self-description in European American and Chinese children. Developmental Psychology, 40(1), 3-15. 10.1037/0012-1649.40.1.3

Wang, Q., \& Peterson, C. (2014). Your earliest memory may be earlier than you think: Prospective studies of children's dating of earliest childhood memories. Developmental Psychology, 50, 1680-1686. doi: http://dx.doi.org/10.1037/a0036001

van der Watt, G., Coall, D., Sng, A., \& Janca, A. (2016). Early memories: Clinical relevance and significance. Australasian Psychiatry, 24, 34-38. doi: 10.1177/1039856215598867

Werner, E. E. (2012). Children and war: Risk, resilience, and recovery. Development and Psychopathology, 24(2), 553-558. doi: 10.1017/S0954579412000156 
Acknowledgements

We are grateful to the children and their families for their participation and to the Academy of Finland (\# 215555) for the financing of the study. This study could not have been realized without the great committed field workers Mohmed Shame, Mohmed Motter, Amel Hossen, Reham Faed, and Ahmed Syied, who worked under extremely harsh conditions in the aftermath of war. We'd like to thank the Ministry of Education, and the headmasters and teachers of the schools who kindly helped us during the data collection. 